\title{
Does Edema Formation Occur in the Rabbit Brain Exposed to Head-Down Tilt?
}

\author{
Reiko SHIMOYAMA*, ${ }^{*}$, Hajime MIYATA ${ }^{\ddagger}$, Eisaku OHAMA ${ }^{\ddagger}$, and Yasuaki KAWAI* \\ Departments of *Physiology and ${ }^{\dagger}$ Ophthalmology, and \\ FDivision of Neuropathology, Institute of Neurological Sciences, \\ Faculty of Medicine, Tottori University, Yonago, 683-8503 Japan
}

\begin{abstract}
Earlier studies showed that exposure to microgravity caused cephalad fluid shift, increased capillary pressure in the head, and produced facial edema and nasal congestion. In the present study, edema formation in the brain was investigated in rabbits exposed to simulated microgravity, head-down tilt (HDT), by measuring water content and histological examinations. Water content in the brain tissues of rabbits exposed to 2 and 8 days of HDT did not increase significantly compared with that of control animals. Neither vital staining using Evans blue nor immunohistochemical examination demonstrated extravasation of plasma constituents in the brain tissues of the HDT rabbits. Although marked
\end{abstract}

congestion was noted in the brain, hematoxylin and eosin staining did not show edematous changes, such as distension of the perivascular and pericellular spaces and vacuolar appearance, in the tissues obtained from HDT rabbits. Transmission electron microscopy revealed that tight junctions of the capillary endothelium were intact in the HDT rabbits. These results suggest that either HDT up to 8 days does not cause brain edema in rabbits or it induces only a slight brain edema which is hard to be demonstrated by measurement of water content or histological examinations. [Japanese Journal of Physiology, $50,141-147,2000]$

Key words: brain edema, microgravity, head-down tilt, capillary pressure, fluid shift.

Mic icrogravity causes a cephalad fluid shift $[1,2]$, which may explain the facial edema and nasal congestion commonly observed in astronauts during spaceflight [1]. Similar symptoms are also found in subjects exposed to head-down tilt (HDT) [3-5]. Thus, HDT has been extensively used to simulate the effects of microgravity on the cardiovascular system. Parazynski and colleagues [5] demonstrated that HDT at $6^{\circ}$ increased capillary pressure in the lip and decreased plasma colloid osmotic pressure. These changes in Starling forces seem to play a major role in the formation of tissue edema in the face.

Exposure to HDT also affects hemodynamics in the brain. Our previous study showed that cerebral blood flow (CBF) velocity increased for at least $6 \mathrm{~h}$ after the onset of $6^{\circ}$ HDT in humans [6]. It is also known that $6^{\circ}$ HDT increases intracranial pressure in humans [7] and monkeys [8]. Elevation of intracranial pressure was also found in our study using rabbits exposed to $45^{\circ}$ HDT [9], in which edema formation was not demonstrated in the brain after $8 \mathrm{~h}$ of $45^{\circ}$ HDT, although venous distension seemed to occur during the experimental period. On the other hand, a morphological study showed that perivascular edema occurred in the monkey brain after 7 days of $6^{\circ}$ HDT [10]. This discrepancy may be attributable to the duration of HDT ( $8 \mathrm{~h}$ vs. 7 days), angle of HDT $\left(45^{\circ}\right.$ vs. $\left.6^{\circ}\right)$, or species difference (rabbit vs. monkey). Exposure to HDT at $45^{\circ}$ in rabbits and $6^{\circ}$ in monkeys increased intracranial pressure by 9.4 [9] and $11.6 \mathrm{mmHg}$ [8], respectively, compared with the values of the control posture (horizontal prone for rabbits and upright sitting for monkeys), suggesting that the hydrostatic effect of HDT is comparable between the two animal

Received on October 7, 1999; accepted on December 18, 1999

Correspondence should be addressed to: Yasuaki Kawai, Department of Physiology, Faculty of Medicine, Tottori University, 86 Nishi-cho, Yonago, 683-8503 Japan. Tel: +81-859-34-8007, Fax: +81-859-34-8008, E-mail: kawai@grape.med.tottori-u.ac.jp

Abbreviation: HDT, head-down tilt. 
Table 1. Animal groups depending on the treatment and examination applied to each animal.

\begin{tabular}{cccl}
\hline Group & Treatment & $n$ & \multicolumn{1}{c}{ Examination } \\
\hline 1 & None & 8 & Water content \\
2 & None & 6 & Histological examination \\
3 & 2 days HDT & 8 & Water content \\
4 & 2 days HDT & 6 & Histological examination \\
5 & 8 days HDT & 8 & Water content \\
6 & 8 days HDT & 6 & Histological examination \\
7 & 2 days CON & 6 & Water content \\
8 & 8 days CON & 6 & Water content \\
\hline
\end{tabular}

n: number of rabbits; HDT: head-down tilt; CON: confinement.

models. Thus, it is interesting to examine whether edema formation also occurs in the brain of rabbits exposed to longer periods of HDT, since the edema may affect cerebral blood flow and intracranial pressure.

In the present experiments, edema formation in the brain was investigated in rabbits exposed to 2 and 8 days of HDT using physicochemical and histological techniques. We hypothesized that edema formation increases water content in the brain tissue and is demonstrated as extravasation of plasma constituents and through histological changes.

\section{MATERIALS AND METHODS}

All procedures used in the present study were reviewed and approved by the Committee for Animal Experimentation of the Faculty of Medicine, Tottori University, Japan, and conformed to all standards set forth in the Guiding Principles for the Care and Use of Animals approved by the Council of the Physiological Society of Japan.

Animals. Fifty-four adult albino rabbits of both sexes $(2.4-3.5 \mathrm{~kg})$ were housed in standard cages and fed laboratory rabbit chow and water ad libitum. The animals were divided into 8 groups as shown in Table 1 , depending on the treatment and examination applied to each animal. The body weight of the rabbits was measured before and after treatment.

Head-down tilt and confinement. Each rabbit in Groups 3 to 6 was put into a handmade jacket which was secured on a plate so that the animal was unable to turn over. The rabbit, however, could move from side to side and get free access to food and water. On the first day of HDT, animals on the plates were fixed in a domestic-made frame, head-down. The angle between the body axis and the floor was set at $30^{\circ}$ to avoid too much stress, since preliminary exper- iments revealed that changing the angle from $0^{\circ}$ directly to $45^{\circ}$ made the animals excited and greatly reduced their food and water intake. On the next day (after $24 \mathrm{~h}$ ), the angle was increased to $45^{\circ}$ and maintained for 1 day ( $24 \mathrm{~h}$ ) in Groups 3 and 4, or for 7 days in Groups 5 and 6. The animals in the confinement groups were also put into the jacket and fixed to the plate in the same way as the rabbits in the HDT groups, but the angle was kept at $0^{\circ}$ throughout the experimental period; 2 days for Group 7 and 8 days for Group 8. After exposure to HDT or confinement, 40 animals were sacrificed with a lethal dose of pentobarbital sodium $(100 \mathrm{mg} / \mathrm{kg}$, Nembutal, Abbott Laboratories, North Chicago, IL, USA). The brain was removed and prepared for the measurement of water content (Groups 3, 5, 7, and 8) or for histological examination (Groups 4 and 6). The animals with no treatment (Groups 1 and 2) served as the controls.

Measurement of water content. Water content was calculated by means of a classic desiccation method [11]. Briefly, brain tissues consisting of the cortex and white matter, weighing $150-250 \mathrm{mg}$, were taken from the frontal and parietal lobes. After measurement of their wet weight using an electronic microbalancer (AB 204, Mettler Toledo Ges m.b.H., Wien, Switzerland), they were dried at $100^{\circ} \mathrm{C}$ in a standard oven for $48 \mathrm{~h}$ and then the dry weight of the samples was determined. The percentage of the water content was calculated using the following equation: $\%$ water content $=[1-($ dry weight $/$ wet weight $)] \times 100$.

\section{Histological examinations}

Evans blue staining. The integrity of the blood-brain barrier was evaluated by vital staining using Evans blue in the rabbits of Groups $2(n=3), 4$ $(n=3)$, and $6(n=3)$. Evans blue dye $(25 \mathrm{mg} / \mathrm{kg}$ in $10 \mathrm{ml}$ saline) was injected intravenously and allowed to circulate for $60 \mathrm{~min}$ before the animals were sacrificed. The brain was removed from the skull and fixed in $4 \%$ paraformaldehyde in $0.1 \mathrm{M}$ phosphate buffer for $24 \mathrm{~h}$. Coronal sections of the brains were made and examined macroscopically.

Histology and immunohistochemistry. The brains obtained from Groups $2(n=3), 4(n=3)$, and 6 $(n=3)$ were fixed in $4 \%$ paraformaldehyde in $0.1 \mathrm{M}$ phosphate buffer for 7 days and processed for paraffin embedding. Sections were cut at $5 \mu \mathrm{m}$ thick, mounted on poly-L-lysine-coated glass, and stained with hematoxylin and eosin. Serial sections were used for immunohistochemistry.

Immunostaining was performed by means of the avidin-biotin-peroxidase complex method. Sections were deparaffinized, rehydrated in a graded ethanol 
Edema Formation during Head-Down Tilt

Table 2. Body weights before and after treatment.

\begin{tabular}{|c|c|c|c|c|c|}
\hline \multirow{2}{*}{ Group (Teatment) } & \multirow{2}{*}{$n$} & \multicolumn{3}{|c|}{ Body weight (kg) } & \multirow{2}{*}{$(A-B) / B \times 100(\%)$} \\
\hline & & Before (B) & $\operatorname{After}(\mathrm{A})$ & $A-B$ & \\
\hline 1 (None) & 8 & $2.96 \pm 0.10$ & - & - & - \\
\hline 2 (None) & 6 & $3.00 \pm 0.07$ & - & - & - \\
\hline 3 (2 days HDT) & 8 & $2.93 \pm 0.08$ & $2.80 \pm 0.09^{*}$ & $-0.13 \pm 0.03$ & $-4.6 \pm 1.2$ \\
\hline 4 (2 days HDT) & 6 & $2.95 \pm 0.08$ & $2.81 \pm 0.08^{*}$ & $-0.14 \pm 0.02$ & $-4.7 \pm 0.8$ \\
\hline 5 (8 days HDT) & 8 & $3.07 \pm 0.10$ & $2.86 \pm 0.09^{*}$ & $-0.21 \pm 0.04$ & $-6.7 \pm 1.1$ \\
\hline 6 (8 days HDT) & 6 & $3.06 \pm 0.07$ & $2.94 \pm 0.06^{\star}$ & $-0.12 \pm 0.02$ & $-3.8 \pm 0.7$ \\
\hline 7 (2 days CON) & 6 & $3.05 \pm 0.10$ & $2.93 \pm 0.07^{\star}$ & $-0.12 \pm 0.04$ & $-4.0 \pm 1.1$ \\
\hline 8 (8 days CON) & 6 & $3.03 \pm 0.07$ & $2.93 \pm 0.07^{*}$ & $-0.10 \pm 0.02$ & $-3.3 \pm 0.6$ \\
\hline
\end{tabular}

$n$ : number of animals. Values are expressed as mean \pm SEM. Before $(B)$ : value before treatment; After $(A)$ : value after treatment; HDT: head-down tilt; CON: confinement; ${ }^{\star} p<0.05$ vs. the value before treatment.

series, washed in distilled water, and treated with $3 \%$ hydrogen peroxide for blocking endogenous peroxidase activity in the tissues. After washing in $0.01 \mathrm{M}$ phosphate-buffered saline, the sections were subjected to $10 \%$ normal donkey serum (Chemicon International Inc. Temecula, CA, USA) to avoid nonspecific binding of secondary antibodies. The sections were then incubated overnight with polyclonal antibody against rabbit serum from goat (diluted $1: 1,000$, ICN Biomedicals, Inc., Aurora, OH, USA) as a primary antibody in a moist chamber at $4^{\circ} \mathrm{C}$. After washing in phosphate-buffered saline, the sections were incubated with a biotinylated donkey anti-goat IgG (diluted $1: 1,000$, Chemicon International Inc.) for $60 \mathrm{~min}$ at $37^{\circ} \mathrm{C}$, treated with the avidin-biotin-peroxidase complex reagent for $60 \mathrm{~min}$, exposed to $0.5 \%$ 3,3'-diaminbentidine $-0.005 \%$ hydrogen peroxide, and finally counterstained with hematoxylin.

Transmission electron microscopy. Small pieces of the parietal cortex were obtained from Groups $2(n=3)$ and $6(n=3)$ for electron microscopy. The specimens were fixed in $2.5 \%$ glutaraldehyde in $0.1 \mathrm{M}$ phosphate buffer for $24 \mathrm{~h}$ and postfixed in $1 \%$ osmium tetroxide overnight at $4^{\circ} \mathrm{C}$. Then they were dehydrated in a graded ethanol series and propylene oxide and embedded in epoxy resin. Ultrathin sections were made using a ultramicrotome (Ultracut UCT Leica, Wien, Austria), stained with uranyl acetate and lead citrate, and examined using a transmission electron microscope (Hitachi, H-7100, Tokyo, Japan) at $75 \mathrm{kV}$.

Data analysis. Data are expressed as means \pm standard error of the mean (SEM). The differences in the mean were statistically analyzed by paired $t$-test between before and after treatment or analysis of variance (ANOVA) followed by a post hoc Fischer's test for multiple comparisons. Statistical significance was
Table 3. Water content in the frontal and parietal lobes of the rabbit brain.

\begin{tabular}{lccc}
\hline \multirow{2}{*}{ Group (Treatment) } & $n$ & \multicolumn{2}{c}{ Water content (\%) } \\
\cline { 3 - 4 } & & Frontal lobe & Parietal lobe \\
\hline 1 (None) & 8 & $80.1 \pm 0.2$ & $79.0 \pm 0.2$ \\
3 (2 days HDT) & 8 & $80.7 \pm 0.4$ & $79.2 \pm 0.4$ \\
5 (8 days HDT) & 8 & $79.6 \pm 0.3^{*}$ & $79.4 \pm 0.3$ \\
$7(2$ days CON) & 6 & $80.2 \pm 0.2$ & $79.4 \pm 0.3$ \\
8 (8 days CON) & 6 & $79.9 \pm 0.3$ & $79.3 \pm 0.2$ \\
\end{tabular}

$n$ : number of animals. Values are expressed as mean \pm SEM. HDT: head-down tilt; CON: confinement; ${ }^{*} p<0.05$ vs. water content in Group 3.

defined as $p<0.05$.

\section{RESULTS}

\section{General findings}

Emotional excitement or any other abnormal behavior was not observed in the animals. During HDT or confinement, food and water intake was less than usual, which caused a decrease in body weight by $3-$ $7 \%$ in Groups 3 to 8 (Table 2).

\section{Water content of the brain tissues}

Water content in the frontal and parietal lobes obtained from the control, HDT and confinement animals are shown in Table 3.

Frontal lobe: Exposure to HDT for 2 days slightly increased the water content, but the difference between Groups 1 and 3 was not statistically significant $(p=0.14)$. The water content in the 8-day HDT group (Group 5) was statistically less $(p<0.05)$ than that in the 2-day HDT group (Group 3). Such a difference was not observed between the confinement groups 

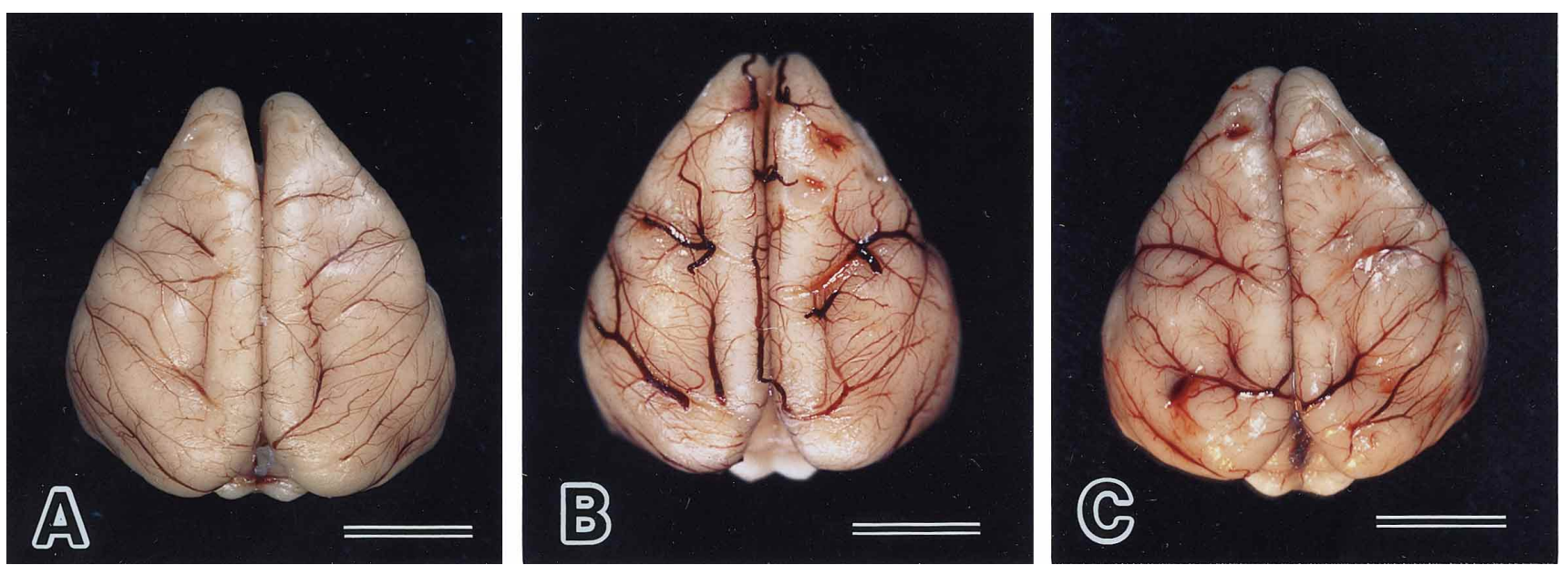

Fig. 1. Macroscopic finding of the brains obtained from the control rabbits (A), 2-day HDT rabbits (B), and 8-day HDT rabbits (C). Congestion of the pial vessels is observed in the brains of HDT rabbits (B, $C)$. Bar $=1 \mathrm{~cm}(A, B, C)$.

\section{(Groups 7 and 8).}

Parietal lobe: Significant differences in the water content of the parietal lobes were not observed between any two groups.

\section{Histological examinations}

Macroscopic findings. Prominent congestion of pial vessels was noted in the brains obtained from HDT rabbits (Fig. 1B and C) but not those from control rabbits (Fig. 1A). The congestion was more marked in the 2-day HDT group (Fig. 1B) than in the 8-day HDT group (Fig. 1C).

Evans blue staining. We assessed the integrity of the blood-brain barrier using Evans blue to examine the presence of plasma leakage in the HDT groups histologically. No leak of Evans blue was found in brain tissues from the 8-day HDT group as well as from the control and 2-day HDT groups (data not shown).

Hematoxylin and eosin staining. Generation of brain edema was assessed by light microscopic examination in both the cortex and white matter of the frontal lobe in the control (Group 2) and HDT groups (Groups 4 and 6). Accumulation of blood in the vessels was marked in the frontal lobe obtained from the 8-day HDT rabbits (Fig. 2) but not in that of the control rabbits (data not shown). However, edematous changes, such as distension of the perivascular and pericellular spaces and the vacuolar appearance of the brain tissues, were not observed in the brain tissues from either the control or HDT groups.

Immunohistochemistry. There was no immunoreactivity for the rabbit serum outside the blood vessels in either the control (data not shown) or HDT groups (Fig. 3).

Transmission electron microscopy. Trans-

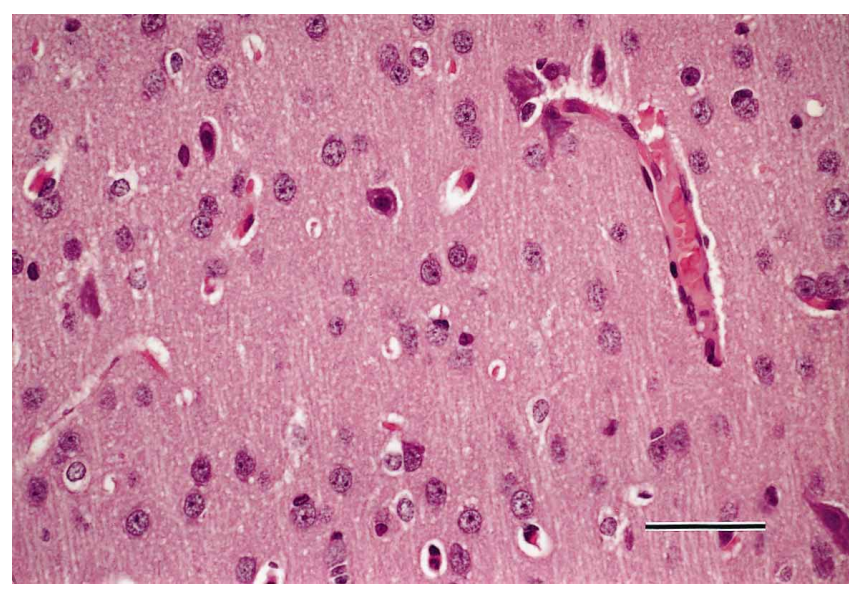

Fig. 2. Light microscopical findings of the cortex in the frontal lobe excised from the 8-day HDT rabbit and stained with hematoxylin and eosin. Edematous changes are not observed. Bar $=50 \mu \mathrm{m}$.

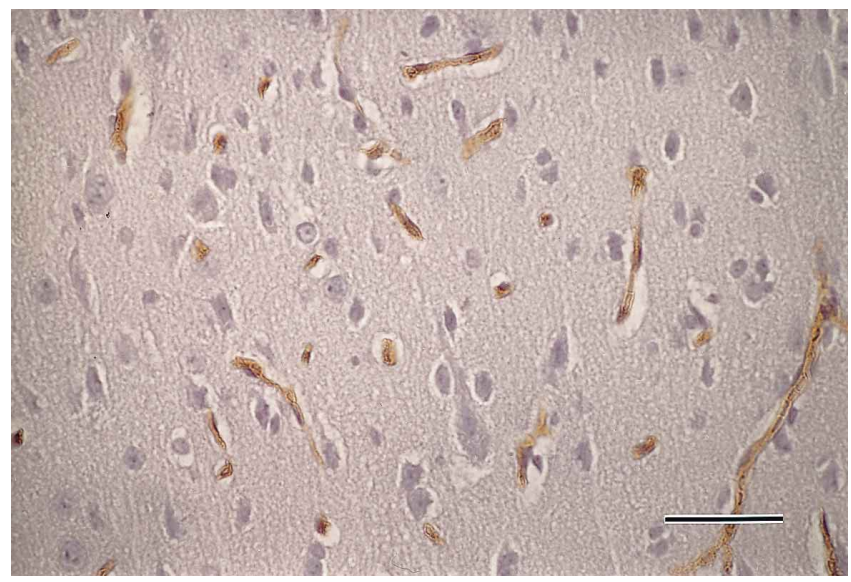

Fig. 3. Immunohistochemical staining of the cortex in the frontal lobe excised from the 8-day HDT rabbit. Immunoreactivities are completely restricted within the vessel lumina, indicating no leakage of serum through the vessel wall. Bar $=50 \mu \mathrm{m}$. 


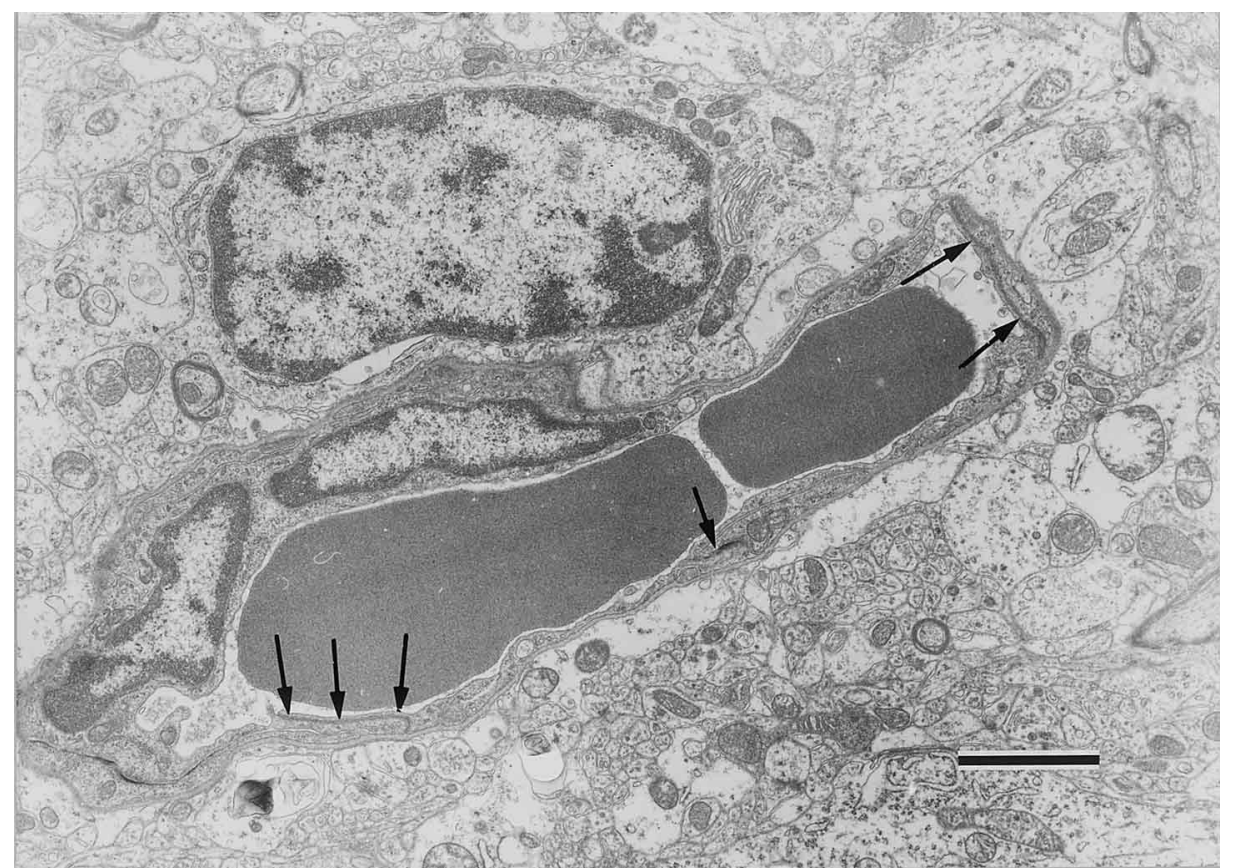

Fig. 4. Transmission electron microscopy of the frontal cortex from the 8-day HDT rabbits. The tight junction (arrow) of the capillary endothelial cells is intact and pinocytotic vesicles are not found. Bar $=2 \mu \mathrm{m}$. mission electron microscopy revealed that there was no significant pathological change in the capillary endothelium in the brains of the HDT group as compared to the controls. Actually, the junctional complex of the capillary endothelium, namely the tight junction, was intact (Fig. 4) in the HDT group. Pinocytotic vesicles in the cytoplasm of the capillary endothelial cells, widening of perivascular spaces and swelling of astrocytic foot processes around the capillaries in the cerebral parenchyma were not observed.

\section{DISCUSSION}

The present results showed that: 1) Water content in the brain tissues of rabbits exposed to 2 and 8 days of HDT did not increase significantly compared with that of control and confinement rabbits, 2) although vasodilation of pial vessels was marked in the HDT group, edema was not observed in either light or electron microscopic examinations, and 3) extravasation of plasma constituents was not demonstrated in the brain tissues of HDT rabbits. These results suggest that $45^{\circ}$ HDT for up to 8 days does not cause marked edema in the frontal and parietal lobes of rabbits. Since we examined only a part of the brain, however, the present results do not rule out a possibility of edema formation in the other parts of the brain including the cerebellum and brainstem.

It is well-known that edema formation increases the water content in brain tissue [12-14]. Our previous study showed that HDT increased water content in the brain tissue of rabbits within $8 \mathrm{~h}$ after its onset, which seemed attributable to the accumulation of blood in the blood vessels and not to edema formation [9]. A similar increase in the water content of the frontal lobe was observed after 2 days of HDT (Table 3), but it was not statistically significant. However, contrary to our expectations, the water content decreased 8 days after the onset of HDT compared with the value after 2 days of HDT. Furthermore, no significant change in water content was observed in the parietal lobe. The reason for the difference between the frontal lobe and parietal lobe is unclear. One possible explanation is that the former was located below the latter during HDT. Thus, blood accumulation in the blood vessels after 2 days of HDT might be more prominent in the frontal lobe than in the parietal lobe. These findings suggest that water content in the brain tissue increases due to blood congestion in the early stage of HDT and then decreases gradually toward the baseline level, and that the change is detectable in the frontal lobe but not in the parietal lobe.

In the present experiments, marked congestion of pial vessels was revealed after 2 days of HDT by both macroscopic finding and light microscopic examination (hematoxylin and eosin staining). The extent of vasodilation was more severe after 2 days of HDT than after 8 days of HDT (Fig. 1). This may explain the significant decrease in the water content of the frontal lobe, which occurred between 2 and 8 days of HDT. The finding that vasodilation became less marked after 2 days of HDT may be explained by two possibilities. First, it is well-known that plasma volume decreases during HDT or tail suspension [15- 


\section{R. SHIMOYAMA et al.}

19]. The decrease in body weight is probably due to increased urinary output $[20,21]$ and less intake of food and water during HDT, which causes dehydration and reduces the plasma volume. In the present study, the body weight decreased in the rabbits of the HDT groups; the difference between before and after HDT being larger in the 8-day HDT group (6.7\% in Group 5 ) than in the 2-day group (4.6\% in Group 3). Such a decrease in body weight is often observed in HDT experiments, and our findings are comparable with those of other studies [20, 22, 23]. Second, the alternative mechanism could be autoregulation of cerebral circulation. Exposure to actual or simulated microgravity elevates blood pressures in cerebral arteries [6] and veins $[24,25]$, and increases the blood flow velocity in the middle cerebral artery $[6,26,27]$. These changes in hemodynamics may cause a constriction of cerebral vessels through myogenic responses [28] or changes in endothelial functions $[28,29]$.

A morphological study revealed that exposure to $6^{\circ}$ HDT for 7 days produced vessel dilatation and perivascular edema in the monkey brain [10]. Wen et al. [30] showed that disruption of the blood-cerebrospinal fluid barrier occurred during $90^{\circ} \mathrm{HDT}$ in rabbits. Parazynski and coworkers [5] demonstrated elevation of the capillary pressure in the human head during HDT. These findings lead us to hypothesize that a sufficient period of HDT will produce vasogenic or hydrostatic edema in brain tissues. Vasogenic edema, the most common form of brain edema, results from breakdown of the blood-brain barrier [13], and is frequently demonstrated by using Evans blue staining [31]. In the present study, however, no plasma leakage was demonstrated by Evans blue staining or immunohistochemistry. Furthermore, electron microscopic examination showed that the tight junctions of the capillary endothelium were intact and pinocytotic vesicles in the endothelial cells were not observed in the HDT group. These results suggest that exposure to $45^{\circ}$ HDT for up to 8 days does not cause vasogenic edema in rabbit brains. Although it is widely accepted that there are no lympatics in the brains of most animals, Bradbury et al. demonstrated that as much as half of the drainage of cerebro-spinal fluid was through lymph in rabbits [32]. Ohhashi et al. [33] demonstrated that venous valves were found in the rabbit jugular vein, whereas there were no valves in the monkey jugular vein. Such differences may explain the discrepancy between the present result and the report by Kaplansky [10], who showed a formation of perivascular edema in the brain of monkeys exposed to 7 days of $6^{\circ}$ HDT. Thus, we have to take account of species difference for analyzing the effect of
HDT. Since plasma leakage has been reported to occur within $1 \mathrm{~h}$ of $90^{\circ} \mathrm{HDT}$ in rabbits [30], the failure to form edema in the present study may be attributable to the angle of HDT but not to the period of HDT. In a previous study, we demonstrated an angledependent change in intracranial pressure during HDT [9]. Therefore, the hydrostatic effect on capillary pressure should be larger in $90^{\circ}$ HDT than in $45^{\circ}$ HDT.

There is still a possibility for brain edema to occur even if the barrier functions are intact, i.e., a hydrostatic edema can occur when the capillary pressure elevates enough to drive water across the capillary wall into the interstitial space. In this type of edema, the capillary endothelium is intact, and only water and small molecules pass through the tight junction. Therefore, Evans blue staining and immunohistochemistry may not detect the edema formation. For now, we cannot rule out the slight possibility that a mild hydrostatic edema occurs during $45^{\circ}$ HDT in rabbits. However, light and electron microscopic examinations showed no histological changes such as distension of perivascular spaces, vacuolar appearance of the tissue or swelling of astrocytic foot processes, which have often been observed in edematous tissues [13].

In conclusion, edema formation was not detected in the brain of rabbits exposed to $45^{\circ}$ HDT for up to 8 days by either measurement of water content or histological examinations. It is important to take account of species difference when the effect of HDT on the hemodynamics in the brain is discussed.

The authors thank Professor A. Tamai, Department of Ophthalmology, Faculty of Medicine, Tottori University, for his critical reading of the manuscript, and Dr. M. Doi for his expert assistance in measuring water content in the brain tissue. This research was supported in part by Grants-in-Aid for Scientific Research (08670051) from the Japanese Ministry of Education, Science, Sports and Culture and the Fund for Basic Experiments Oriented to Space Station Utilization (U-48).

\section{REFERENCES}

1. Thornton WE, Moore TP, and Pool SL: Fluid shifts in weightlessness. Aviat Space Environ Med 58: A86A90, 1987

2. Hargens AR and Watenpaugh DE: Cardiovascular adaptation to spaceflight. Med Sci Sports Exerc 28: 977-982, 1996

3. Montgomery LD, Parmet AJ, and Booher CR: Body volume changes during simulated microgravity: auditory changes, segmental fluid redistribution, and regional hemodynamics. Ann Biomed Eng 21: 417-433, 1993

4. Blomqvist CG, Nixon JV, Johnson Jr RL, and Mitchell $\mathrm{JH}$ : Early cardiovascular adaptation to zero gravity simulated by head-down tilt. Acta Astronaut 7: 543-553, 
1980

5. Parazynski SE, Hargens AR, Tucker B, Aratow M, Styf $J$, and Crenshaw A: Transcapillary fluid shifts in tissues of the head and neck during and after simulated microgravity. J Appl Physiol 71: 2469-2475, 1991

6. Kawai Y, Murthy G, Watenpaugh DE, Breit GA, Deroshia CW, and Hargens AR: Cerebral blood flow velocity in humans exposed to $24 \mathrm{~h}$ of head-down tilt. $\mathrm{J}$ Appl Physiol 74: 3046-3051, 1993

7. Murthy G, Marchbanks RJ, Watenpaugh DE, Meyer JU, Eliashberg N, and Hargens AR: Increased intracranial pressure in humans during simulated microgravity. Physiologist 35: S184-S185, 1992

8. Keil LC, McKeever KH, Skidmore MG, Hines J, and Severs WB: The effect of head-down tilt and water immersion on intracranial pressure in nonhuman primates. Aviat Space Environ Med 63: 181-185, 1992

9. Doi M and Kawai Y: Mechanisms of increased intracranial pressure in rabbit exposure to head-down tilt. Jpn J Physiol 48: 63-69, 1998

10. Kaplansky AS, Savina EA, Kazakova PB, KhoroshilovaMaslova IP, Kharin GM, Yakovleva VI, PlakhutaPlakutina GI, Durnova GN, Ilyina-Kakueva El, Alekseev EI, Pankova AS, Shvets VN, and Burkovskaya TN: Antiorthostatic hypokinesia in monkeys: morphological examination. Kosmo Biol Aviakosm Med 19: 53-60, 1985

11. Marmarou A, Poll W, Shulman $K$, and Bhagavan $H$ : $A$ simple gravimetric technique for measurement of cerebral edema. J Neurosurg 49: 530-537, 1978

12. Schwab M, Bauer R, and Zwiener U: The distribution of normal brain water content in Wister rats and its increase due to ischemia. Brain Res 749: 82-87, 1997

13. Miller JD and Ironside JW: Raised intracranial pressure, oedema and hydrocephalus. In: Greenfield's Neuropathology, ed. Graham DI and Lantos PL, Arnold, London, Vol 1, pp 157-195, 1997

14. Chen Y, Constantini S, Trembovler V, Weinstock M, and Shohami E: An experimental model of closed head injury in mice: pathophysiology, histopathology, and cognitive deficits. J Neurotraum 13: 557-568, 1996

15. Sigaudo D, Fortrat JO, Maillet A, Allevard AM, Traon $A P L$, Hughson RL, Güell A, Gharib C, and Gauquelin G: Comparison of a 4-day confinement and head-down tilt on endocrine response and cardiovascular variability in humans. Eur J Appl Physiol 73: 28-37, 1996

16. Beck L, Baisch F, Gaffney FA, Buckey JC, Arbille PH, Patat F, Ten Harkel ADJ, Hillebrecht A, Schulz H, Karemaker JM, Meyer M, and Blomqvist CG: Cardiovascular response to lower body negative pressure before, during, and after ten days head-down tilt bed rest. Acta Physiol Scand 144 (S604): 43-52, 1992

17. Breeze BL and Walker BR: Altered baroreflex function after tail suspension in the conscious rat. J Appl Physiol 69: 2091-2096, 1990

18. Branch JD III, Pate RR, Bodary PF, and Convertino VA: Red cell volume and [erythropoietin] responses during exposure to simulated microgravity. Aviat Space Envi- ron Med 69: 347-351, 1998

19. Convertino VA, Engelke KA, Ludwig DA, and Doerr DF: Restoration of plasma volume after 16 days of headdown tilt induced by a single bout of maximal exercise. Am J Physiol 270: R3-R10, 1996

20. Deavers DR, Musacchia XJ, and Meininger GA: Model for antiorthostatic hypokinesia: head-down tilt effects on water and salt excretion. J Appl Physiol: Respirat Environ Exercise Physiol 49: 576-582, 1980

21. Pamnani MB, Mo Z, Chen S, Bryant HJ, White RJ, and Haddy FJ: Effects of head down tilt on hemodynamics, fluid volumes, and plasma Na-K pump inhibitor in rats. Aviat Space Environ Med 67: 928-934, 1996

22. Overton JM and Tipton CM: Effect of hindlimb suspension on cardiovascular responses to sympathomimerics and lower body negative pressure. J Appl Physiol 68: 355-362, 1990

23. Overton JM, Woodman CR, and Tipton CM: Effect of hindlimb suspension on $\mathrm{VO}_{2 \max }$ and regional blood flow responses to exercise. J Appl Physiol 66: 653-659, 1989

24. Kotani J, Momota Y, Sugioka S, Umemura A, and Ueda $Y$ : Effect of head-down tilt on intracranial pressure and sagittal sinus pressure during general anesthesia in cats. Anesthesiol Prog 39: 209-211, 1992

25. Kotani J, Adachi R, Fujita N, Sugioka S, and Ueda Y: Effect of cerebral venous congestion on the pressurevolume index in the evaluation of intracranial pressure dynamics. J Neurosurg Anesthesiol 5: 121-126, 1993

26. Bagian JP and Hackett P: Cerebral blood flow: comparison of ground-based and spaceflight data and correction with space adaptation syndrome. J Clin Pharmacol 31: 1036-1040, 1991

27. Kawai Y, Murthy G, Watenpaugh DE, and Hargens AR: Cerebral blood flow velocity increases with acute head-down tilt of humans. Physiologist 35: S186-S187, 1992

28. Geary GG, Krause DN, Purady RE, and Duckers SP: Simulated microgravity increases myogenic tone in rat cerebral arteries. J Appl Physiol 85: 1615-1621, 1998

29. Cardello LO, Uddman R, and Edvinsson L: Endothelins: a role in cerebrovascular disease? Cephalalgia 14: 259-265, 1994.

30. Wen TS, Randall DC, and Zolman JF: Protein accumulation in cerebrospinal fluid during $-90^{\circ}$ head-down tilt in rabbit. J Appl Physiol 77: 1081-1086, 1994

31. Belayev L, Busto R, Zhao W, and Ginsberg MD: Quantitative evaluation of blood-brain barrier permeability following middle cerebral artery occlusion in rats. Brain Res 739: 88-96, 1996

32. Bradbury MWB, Cserr HF, and Westrop RJ: Drainage of cerebral interstitial fluid into deep cervical lymph of the rabbit. Am J Physiol 240: F329-F336, 1981

33. Ohhashi T, Morimoto-Murase K, and Kitoh T: Physiology and functional anatomy of the venous system. In: Veins: Their Functional Role in the Circulation, ed. Hirakawa S, Rothe CF, Shoukas AA, and Tyberg JV, Springer-Verlag, Tokyo, pp 33-47, 1993 